\title{
LINKS BETWEEN MOISTURE CONTENT OF BIOMASS OF (CREMASTRA APPENDICULATA) AND ELEVATIONS BY LONG-TIME INVESTIGATION AND QUALITATIVE ANALYSIS AND QUANTITATIVE STATISTICS OF "BIG DATA"
}

\author{
Bing-Hua Liao ${ }^{1,2}$ \\ (1.The Key Laboratory of Ecological Restoration in Hilly Areas, Forestry Department of Henan Province, Institute of chemistry and \\ environmental engineering, Ping-ding-shan University, Ping-ding-shan City, 467000, China; 2. Institute of life and science, Henan \\ University, Kai-feng City, He-nan Province, 475004, China)
}

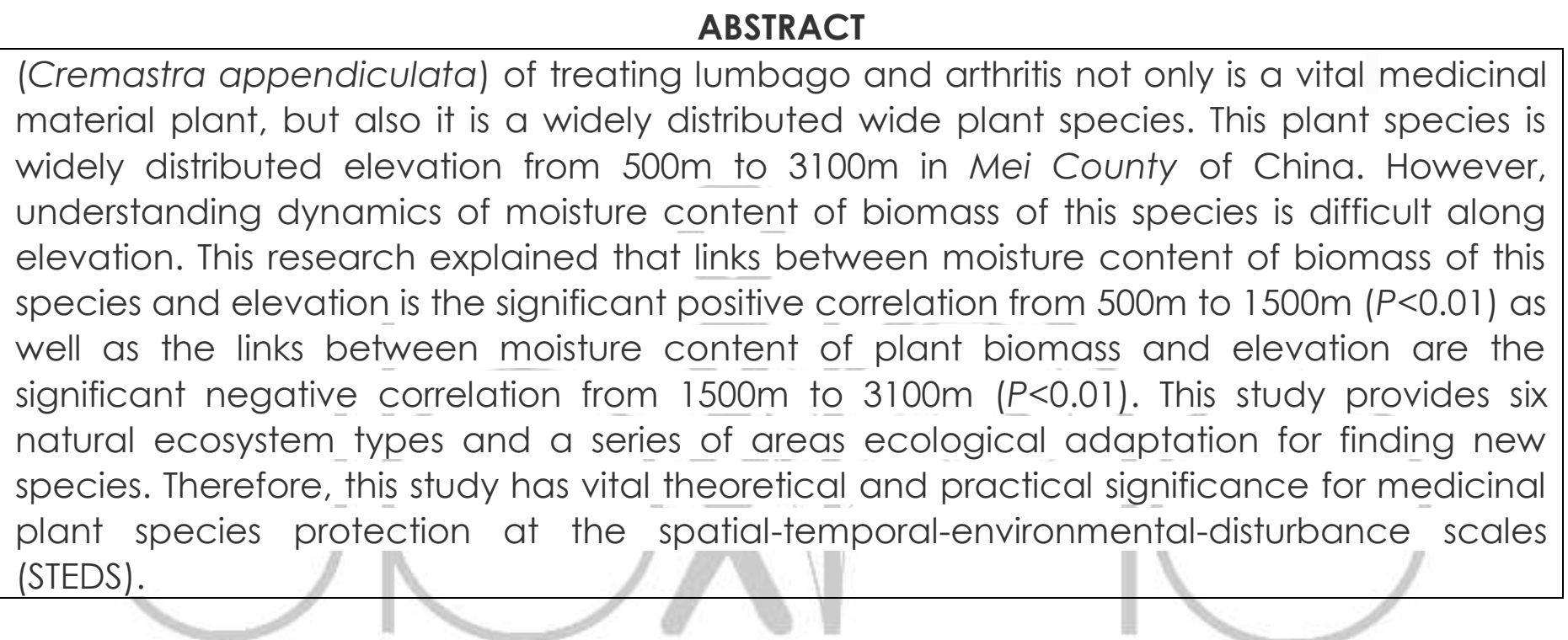

Key Words: moisture content of biomass; elevation; links; areas ecological adaptation; medicinal species. 


\section{INTRODUCTION}

More and more research has assessed the correlation among biomass (average height, numbers, biodiversity) of plant species and elevation from biomass (average height, numbers. biodiversity) of the medicinal plant perspective (Table 1)1-11 for better future of human health (ecosystems)6-11. However, medicinal species with typical history spanning over 1500 years, and areas ecological adaptation of a lot of moisture content of biomass are unknown, as well as cognitive ecological theory of links between moisture content of biomass and elevation gradient can be unknown ${ }^{12-19}$.

Thus, understanding these medical values of medicinal spices, as well as the links between moisture content of biomass of different areas ecological adaptation and elevation gradient is a vital ecological rule along elevation and environmental gradient in the natural ecosystem types.

(Cremastra appendiculata) not only is vital medicinal material of treating lumbago and arthritis, but also is widely distributed wide specie in Mei County of China. This specie is belonging to Cremastra genus of Orchidaceae families of Monocotyledoneae in Angiospermae. Understanding moisture content of this species biomass is unknown, however. Indeed, our research not only explained that there are links between moisture content of this species biomass and elevation, but also explained that this species is a plant treating lumbago and arthritis by better future of human health and ecosystem functions, ecosystem services and ecosystem procession.

Therefore, there are some vital rules that the correlations between moisture content of this plant species biomass of (Cremastra appendiculata) vital medicinal material of treating lumbago and elevation in vegetation landscapes of Mei County of China at the STEDS.

Abbreviation: STEDS, the spatial-temporal-environmental-disturbance scales.

Table.1 Links between medicinal plant biomass (number, height, biodiversity) and elevation

Links between medicinal plant biomass (biodiversity, height) and elevation

Authors

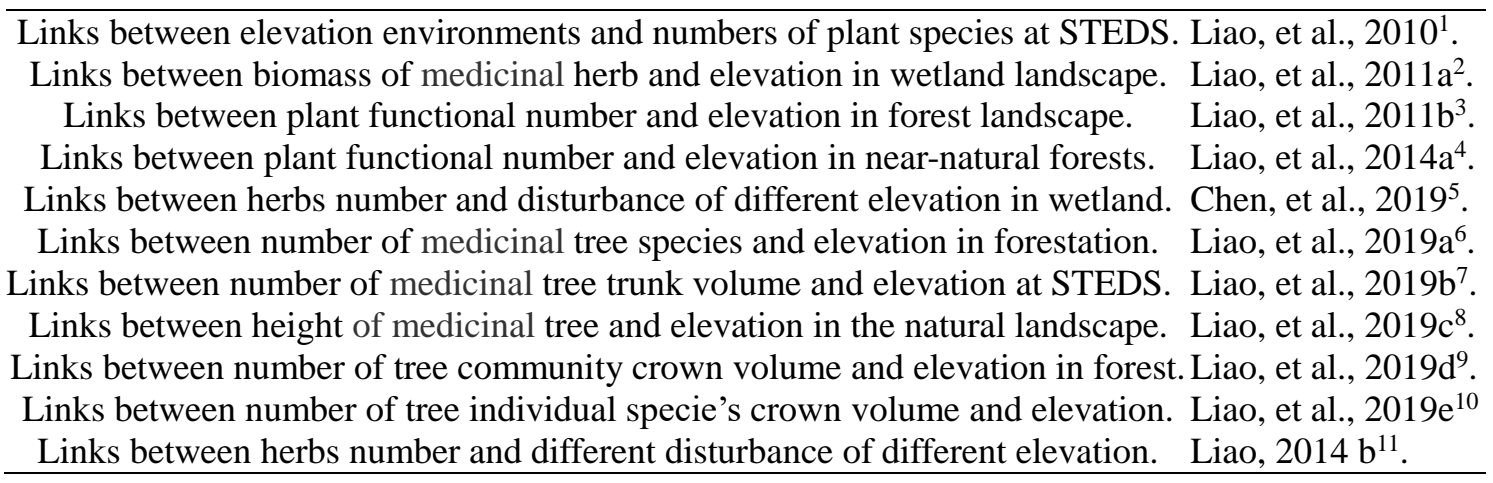




\section{Typical environmental condition, situation of typical vegetation and methods of research}

Typical area is local in three zones: firstly, evergreen vegetation of north subtropical zone; secondly, evergreen and deciduous coniferous and broad-leaved mixed forest of north subtropical and warm temperate transition; thirdly, deciduous vegetation of warm temperate zone in Earth. Thus, our research area is local in evergreen and deciduous coniferous and broad-leaved mixed forest in north subtropical and warm temperate transition in Mei County of China (Figure 1).

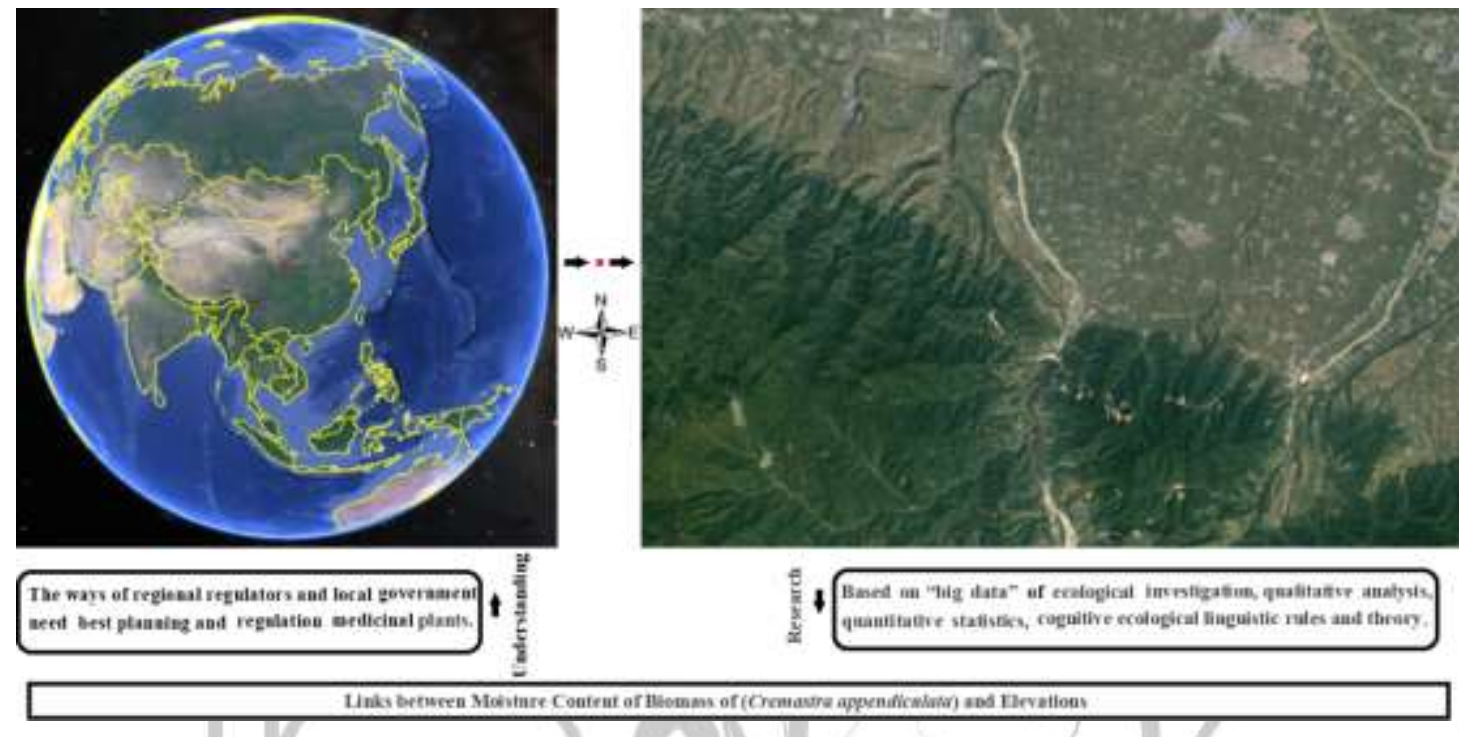

Figure 1. A Digital Cadaster Map and Research Methods of Typical Location in Mei County of China of Earth.

There are long-time investigation of links between moisture content of medicinal plant biomass and elevation from 2005 to 2019. Investigation of "big data" included that moisture content of medicinal plant or other index of plant species along environments by our previous researches-11.

Thus, there is the links between moisture content of medicinal plant biomass and elevation, as well as there is a series of (good, better, best) natural landscapes areas ecological adaptation of moisture content of medicinal plant biomass by the "big data" of the ecological investigation, qualitative analysis, quantitative statistics, human cognitive ecological linguistic rules, theories, methods and ways along elevation and environmental gradient at the STEDS by the long-time wild investigation and qualitative analysis and quantitative statistics of "Big Data"4-25. 


\section{Results and Analysis}

Based on "big data" of plant species investigation, this species is a widely distributed wide species along elevation from $500 \mathrm{~m}$ to $3100 \mathrm{~m}$. (Cremastra appendiculata) is a widely distributed along elevation from $500 \mathrm{~m}$ to $3100 \mathrm{~m}$ in Mei County of China. However, understanding the elevation effect on the links between moisture content of plant species biomass and elevation is very difficult, because elevation effect on moisture content $\mathrm{O}$ medicinal plant biomass 2-16, 20-26.

Using the dynamics of "big data" investigation, this research suggested there are four rules:

Firstly, this research suggested that there is not only increasing of moisture content of (Cremastra appendiculata) biomass with increasing of elevation from $500 \mathrm{~m}$ to $1500 \mathrm{~m}$, as well as there are but also decreasing of moisture content of (Cremastra appendiculata) biomass with increasing of elevation from $1500 \mathrm{~m}$ to $3100 \mathrm{~m}$ at the STEDS in Mei County of China (Figure 2).

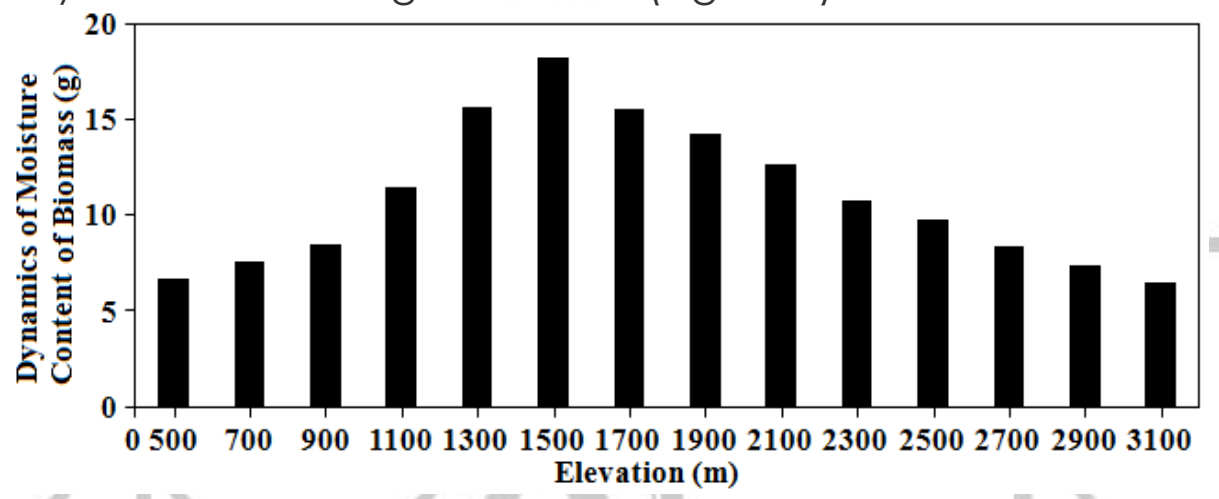

Figure2. Dynamics of Moisture Content of this Species Biomass along Elevation Gradient

Secondly, this study explained that there is the significant positive correlations between moisture content of (Cremastra appendiculata) biomass and elevation from $500 \mathrm{~m}$ to $1500 \mathrm{~m}$ along elevation gradient $(P<0.01)$, and there is the significant negative correlations between moisture content of (Cremastra appendiculata) biomass and elevation from $1500 \mathrm{~m}$ to $3100 \mathrm{~m}$ along elevation gradient at STEDS in Mei County of China $(P<0.01)$ (Table 2).

Table.2 Correlation between Moisture Content of Biomass and Elevation Gradient

\begin{tabular}{ccc}
\hline Elevation $(\mathrm{m})$ & Elevation From $500 \mathrm{~m}$ to $1500 \mathrm{~m}$ & Elevation From $150 \mathrm{~m}$ to $3100 \mathrm{~m}$ \\
\hline moisture content of biomass & $0.968^{* *}$ & $-0.990^{* *}$ \\
\hline Note: $* *, P<0.01$. & &
\end{tabular}

Thirdly, this research provides a good areas ecological adaptation of (Cremastra appendiculata) from $500 \mathrm{~m}$ to 3100 in Mei County in China. Meanwhile, this research proposed that there is not only the better area ecological adaptation of (Cremastra appendiculata) from $1000 \mathrm{~m}$ to $2000 \mathrm{~m}$, there is but also the best areas ecological adaptation of (Cremastra appendiculata) from 1300 m to $1700 m$; because there are 
results that there are not only dynamics of different air environmental factors, there are but also dynamics of different soil environmental factors from $500 \mathrm{~m}$ to $3100 \mathrm{~m}$ by dynamics of moisture content of (Cremastra appendiculata) biomass in Mei County (Figure 2).

Fourthly, this research proposed that medicinal plant species (Cremastra appendiculata) is local in six natural ecosystem (mixed natural ecosystem between forestation and grassland, natural forestation ecosystem, mixed natural ecosystem between forestation and wetland, mixed natural ecosystem between river and forestation, mixed natural ecosystem between forestation and urban, mixed natural ecosystem between forestation and rural settlement) by the "big data" of moisture content of (Cremastra appendiculata) biomass investing along elevation, because there may be results that there are not only dynamics of air environments, there are but also dynamics of soil environmental factors from $500 \mathrm{~m}$ to $3100 \mathrm{~m}$ by the dynamics of moisture content of (Cremastra appendiculata) biomass along elevation gradient at STEDS in Mei County of China.

Thus, this research found a series of typical (good, better, best) areas ecological adaptation of (Cremastra appendiculata) of treating lumbago and arthritis along elevation gradient, as well as there is the links between moisture content of this plant biomass and elevation gradient at STEDS.

\section{Conclusion and Discussion}

Understanding medicinal plant species is very difficult1-16, 27- 33. This research suggested three rules between moisture content of (Cremastra appendiculata) biomass and elevation gradient:
1. This research suggested that there is increasing of moisture content of (Cremastra appendiculata) biomass with increasing of elevation from $500 \mathrm{~m}$ to $1500 \mathrm{~m}$, as well as there is decreasing of moisture content of (Cremastra appendiculata) biomass with increasing of elevation from $1500 \mathrm{~m}$ to $3100 \mathrm{~m}$ (Figure 2). There is the significant positive correlation between moisture content of (Cremastra appendiculata) biomass and elevation from $500 m$ to $1500 m(P<0.01)$ as well as there is the significant negative correlation between moisture content of (Cremastra appendiculata) biomass and elevation from $1500 \mathrm{~m}$ to $3100 \mathrm{~m}$ along elevation $(P<0.01)$ (Table 2).

2. This research provides six natural ecosystem types (forestation, mixed between forestation and grassland, mixed between forestation and wetland, mixed between forestation and river, mixed between forest and urban, mixed between forestation and rural settlement), as well as there is a series of areas ecological adaptation la good areas ecological adaptation from $500 \mathrm{~m}$ to 3100 , the better area ecological adaptation from $1000 \mathrm{~m}$ to $2000 \mathrm{~m}$, the best areas ecological adaptation from $1300 \mathrm{~m}$ to $1700 \mathrm{~m}$ ) for finding (Cremastra appendiculata) by dynamics of moisture content of (Cremastra appendiculata) biomass at STEDS in Mei County of China.

3. (Cremastra appendiculata) not only is a vital medicinal material of treating lumbago and arthritis,but also it is belonging to Cremastra genus of Orchidaceae families of Monocotyledoneae in Angiospermae, as well as it is widely distributed wide specie by the "big data" long-time investigation of moisture content of (Cremastra appendiculata) biomass in Mei County at STEDS. 
Therefore, this research has a vital theoretical and practical significance for the reasonable protection of (Cremastra appendiculata) along different elevation gradient in the different ecosystems, because this plant species not only is an important widely distributed wide medicinal material pant by treating lumbago and arthritis, but also there are three rules by the links between moisture content of (Cremastra appendiculata) biomass and elevation in Mei County of China. Indeed, better regional regulators and local government need better planning and regulation a lot of medicinal plant management sustainability of communities by the research on moisture content of (Cremastra appendiculata) biomass (biodiversity, height, number, et al.) based on dynamics of linkages among biodiversity, elevation, environmental factors in local, regional, global ecosystems for better future of ecosystem services and human health at the STEDS by the long-time wild investigation and qualitative analysis and quantitative statistics of "Big Data"1-15,34-41.

\section{Acknowledgement}

This work was supported by A Grade of Key Disciplines of Environmental Science Foundation, B Grade of Key Disciplines of Mistrials Science of Ping-Ding-shan University in China; Science and Technology Department of He'nan Province Foundation (KJT-17202310242; 092102110165); Subprojects by Intergovernmental Platform on Biodiversity and Ecosystem Services (IPBES); and better ideas of researchers of "1st Biotechnology World Congress" in 2011, "2st Biotechnology World Congress" in 2012, "3st Biotechnology World Congress" in 2013 is appreciated.

\section{References}

1. Liao BH, Wang XH. Plant functional group classifications and a generalized hierarchical framework of plant functional traits, African Journal of Biotechnology, 2010, 9:9208-9213.

2. Liao BH, Ding SY, Liang GF, et al. Dynamics of plant functional groups composition along environmental gradients in the typical area of Yi-Luo River watershed. African Journal of Biotechnology, 2011 a, 10:14485- 14492.

3. Liao BH, Ding SY, Hu N, et al. Dynamics of environmental gradients on plant functional groups composition on the northern slope of the Fu-Niu Mountain Nature Reserve. African Journal of Biotechnology, $2011 \mathrm{~b}, 10: 18939-18947$.

4. Liao BH, LiU QF, LU D, et al. Dynamics of environmental gradients on plant functional groups composition species in near-natural community ecological restoration on the southern slope of the Fu-Niu Mountain Nature Reserve. Journal of Science, 2014a, 4:306-312.

5. Chen HS, Liao BH, Hang CZ,et al. Research on risk assessment and early warning mechanism of agricultural non-point source pollution in Bai-gui Lake watershed by GIS. International Journal of Pharmacognosy and Pharmaceutical Sciences, 2019, 1:25-29.

6. Liao BH,Liu M.,Huang CZ.,et al.Dynamics of(Sophora japonica)Community's Tree Individual Number along Elevation Gradient in Ye County. International Journal of Pharmacognosy and Pharmaceutical Sciences, 2019a, 1:1-4. 7. Liao BH, Liu YP, Zuo H, et al. Dynamics of 18 (Sophora japonica) Tree Community's Total Trunk Volume along Elevation Gradient in Ye County. International Journal of Current Advanced Research, 2019c, 
8:19063-19066.

8. Liao BH, Liu YP, Zuo H, et al. Elevation Dynamics of (Sophora japonica) Community's Height in Ye County. International Journal of Research Pharmaceutical and Nano Sciences, 2019b, 8:48 -54.

9. Liao BH, Liu YP, et al. Dynamics Crown Volume of 18 (Sophora japonica) Tree Communities along Elevation Gradient in Ye County. Open Journal of Ecology, 2019d, 9:209 -215.

10. Liao BH, Liu YP, Zuo H, et al. Dynamics of 18 (Sophora japonica) Tree Individual specie's Crown Volume along Elevation Gradient in Ye County. International Journal of Research Pharmaceutical and Nano Sciences, 2019e, 8:62-68.

11. Liao BH. A new model of dynamic of plant diversity in changing farmlands, implications for the management of plant biodiversity along differential environmental gradient in the spring. African Journal of Environmental Science and Technology, 2014b, 8:171177.

12. Zhu DM, Liao BH. A dynamical system of human cognitive linguistic theory in learning and teaching of the typical university in Henan Province. International Journal of Pharmacy \& Therapeutics, 2015, 6: 4-6.

13. Yang $Y$, Sun $M$, et al. Germplasm resources and genetic breeding of Paeonia: a systematic review. Horticulture Research, 2020, 7:1-19.

14. Jin D, Dai KP, et al. Secondary Metabolites Profiled in Cannabis Inflorescences, Leaves, Stem Barks, and Roots for Medicinal Purposes. Scientific Reports, 2020, 10: 1-14.

15. Kozuharova E, Matkowski A, et al. Amorpha fruticosa - A Noxious Invasive Alien Plant in Europe or a Medicinal Plant against Metabolic Disease? Front
Pharmacol., 2017, 8: 333.

16. Giovannini P, Howes MJ, Edwards SE. Medicinal plants used in the traditional management of diabetes and its sequelae in Central America: A review. J Ethnopharmacol., 2016, 184:58-71.

17. Szopa A, Klimek-Szczykutowicz $M$, Kokotkiewicz A, et al. Phenolic acid and flavonoid production in agar, agitated and bioreactor-grown microshoot cultures of Schisandra chinensis Cv. Sadova No.1 - a valuable medicinal plant. J Biotechnol., 2019, 305: 61- 70.

18. Mesfin F, Demissew S, Teklehaymanot T. An ethnobotanical study of medicinal plants in Wonago Woreda, SNNPR, Ethiopia. J Ethnobiol Ethnomed., 2009, $5: 28$.

19. Elkins AC, Deseo MA, Rochfort $S$, et al.Development of a validated method for the qualitative and quantitative analysis of cannabinoids in plant biomass and medicinal cannabis resin extracts obtained by super-critical fluid extraction. J Chromatogr B Ánalyt Technol Biomed Life Sci., 2019, 109:76-83.

20. Baque MA, Moh SH, Lee EJ, et al. Production of biomass and useful compounds from adventitious roots of high-value added medicinal plants using bioreactor. Biotechnol Adv., 2012, 30:1255-1267.

21. Saeed S, Ali H, Khan T, et al. Impacts of methyl jasmonate and phenyl acetic acid on biomass accumulation and antioxidant potential in adventitious roots of Ajuga bracteosa Wall ex Benth., a high valued endangered medicinal plant. Physiol Mol Biol Plants., 2017, 23: 229- 237.

22. Prasad R, Kamal S, Sharma PK, et al.Root endophyte Piriformospora indica DSM 11827 alters plant morphology, enhances biomass and 
antioxidant activity of medicinal plant Bacopa monniera. J Basic Microbiol., 2013, 53:1016-1024.

23. Fuentes $P$, Zhou F, Erban A, et al.A new synthetic biology approach allows transfer of an entire metabolic pathway from a medicinal plant to a biomass crop. Elife., 2016, 5:e 1360-1364.

24. Rukh G, Ahmad $\mathrm{N}$, et al. Photodependent somatic embryogenesis from non-embryogenic calli and its polyphenolics content in high-valued medicinal plant of Ajuga bracteosa. J Photochem Photobiol B., 2019, 190:59-65.

25. Das A, Kamal S, Shakil NA, et al. The root endophyte fungus Piriformospora indica leads to early flowering, higher biomass and altered secondary metabolites of the medicinal plant, Coleus forskohlii. Plant Signal Behav., 2012, 7:103-112.

26. Schafhauser T, Jahn L, Kirchner $\mathrm{N}$, et al. Antitumor astins originate from the fungal endophyte Cyanodermella asteris living within the medicinal plant Aster tataricus. Proc Natl Acad Sci USA. $2019,116: 26909-26917$.

27. Singh SP, Gaur R. Evaluation of antagonistic and plant growth promoting activities of chitinolytic endophytic actinomycetes associated with medicinal plants against Sclerotium rolfsii in chickpea.J Appl Microbiol., 2016, 121:506-518.

28. Bojić $M$, Maleš Ž, Antolić $A$, et al. Antithrombotic activity of flavonoids and polyphenols rich plant species. Acta Pharm., 2019, 69:483-495.

29. Maleš Ž, Drvar DL, et al. Application of medicinal plants in several dermatovenerological entities. Acta Pharm., 2019, 69:525-531.

30. Wyk BEV. A review of commercially important African medicinal plants. J
Ethnopharmacol., 2015, 176:118-134.

31. Das K, Dang R, Shivananda TN, Sur P. Interaction between phosphorus and zinc on the biomass yield and yield attributes of the medicinal plant stevia (Stevia rebaudiana). Scientific World Journal, 2005, 5:390-395.

32. Zubek S, Mielcarek S, Turnau K. Hypericin and pseudohypericin concentrations of a valuable medicinal plant Hypericum perforatum L. are enhanced by arbuscular mycorrhizal fungi. Mycorrhiza., 2012, 22:149-156.

33. Takshak S, Agrawal SB. Defence strategies adopted by the medicinal plant Coleus forskohlii against supplemental ultraviolet-B radiation: Augmentation of secondary metabolites and antioxidants. Plant Physiol Biochem., 2015, 97:124-138.

34. Larsen $\mathrm{HO}$. Commercial medicinal plant extraction in the hills of Nepal: local managementsystem and ecological sustainability, Environ Manage., 2002, 29:88-101.

35. Ali H, Khan MA, Kayani WK, et al. Production of biomass and medicinal metabolites through adventitious roots in Ajuga bracteosa under different spectral lights. J Photochem Photobiol B., 2019, 193:109-117.

36. Wilson RJ, Thomas CD, et al. Spatial patterns in species distributions reveal biodiversity change. Nature, 2004, 432, 393-396.

37. Larigauderie A., Mace GM, Mooney HA. Colour-coded targets would help clarify biodiversity priorities. Nature, 2010, 464, 160.

38. Song H, Payne S, et al. Spatiotemporal modulation of biodiversity in a synthetic chemical- mediated ecosystem. Nature Chemical Biology, 2009, 5:929-935.

39. Opgenoorth L, Hotes S, Mooney H. IPEPS: 
Biodiversity panel should play by rules.

Nature, 2014, 506:159.

40. Wickson F. Mosquotoes: just how much biodiversity does humanity need? Nature, 2010, 466: 1041.

41. Liao, Mace GM, Ekins P. Limits to agricultural land for retaining acceptable levels of local biodiversity. Nature Sustainability, 2019, 2: 491-498. 